\title{
Acta Cirúrgica Brasileira no JCR - 2009
}

\author{
Acta Cirúrgica Brasileira in 2009 JCR Science Edition
}

\author{
Saul GoldenbergI, Alberto Goldenberg", Edna Frasson de Souza Montero ${ }^{\text {III }}$ \\ I Fundador, Editor Chefe \\ II Editor Científico \\ III Editor Associado
}

AActa Cirúrgica Brasileira tem galgado os degraus da classificação ao seguir os critérios estabelecidos para indexação nas bases de dados.

Em junho de 2010, saiu o seu primeiro Fator de Impacto no JCR, desde a sua indexação na base ISI - Thomson Reuters. Fator de Impacto de 0,479; muito próximo do 0,551 previsto por Meneghini ${ }^{1}$. No número anterior, Caló ${ }^{1}$ comenta sobre o Fator de Impacto e sua valorização como índice qualificador da produção científica no Brasil. Também compartilhamos da opinião de que devemos ter outra forma de avaliar a produção científica para definir, a partir daí, fomentos, nota dos programas de pós-graduação e categorização dos docentes.

Destaque-se que, na área da Cirurgia, a ACTA é a única revista brasileira no JCR. Nós do Corpo Editorial estamos muito gratificados com o resultado alcançado.

Este é um feito extraordinário. Estamos mesmo de parabéns.

\section{Referência}

1. Caló LN. A Acta Cirúrgica Brasileira e o Journal Citation Reports. Editorial. Acta Cir Bras. 2010;25(3):217. 